\title{
Equations Used to Calculate Vertical Bearing Capacity of Driven Piles with Shaft Broadenings
}

\author{
Isabai Bekbasarov ${ }^{1}$, Yerlan Atenov ${ }^{2 *}$ \\ ${ }^{1}$ Geotechnical Testing Laboratory, Dulaty University, Campus 2.1, 60, Tole bi, 080000, Taraz, Kazakhstan \\ ${ }^{2}$ Department of Water Resources and Hydraulic Structures, Faculty of Water Management and Construction, Dulaty University, \\ Campus 6.2, 28, Satpayev, 080012, Taraz, Kazakhstan \\ *Corresponding author, e-mail: yer_at@mail.ru
}

Received: 19 May 2020, Accepted: 23 July 2020, Published online: 16 September 2020

\begin{abstract}
In a pile foundation setting practice driven piles with an unconventional (variable) longitudinal shape of surface are widely used. Such piles are made with various slopes of the side faces, may have different types of broadenings, thickenings, etc. The effectiveness of such piles is due to their design features, allowing full use of the natural bearing capacity of the soil base without additional reinforcement. The obvious advantages of these piles make it relevant to study the features of their interaction with the soil stratum, especially the bearing capacity of piles. This study was aimed to investigate vertical bearing capacity of driven reinforced concrete piles with several broadening of the shaft. Numerical calculations and experimental studies of the bearing capacity of piles with broadening under the static loading have been carried out. Equations for calculating the bearing capacity of piles with broadenings are proposed and their verification is performed. The equations include a coefficient that takes into account the features of soil behavior underneath of the pile broadening during palification. Correlation dependence is presented which makes it possible to determine the values of that coefficient depending on the number of pile broadening and the liquidity index of soil. A correlation that makes allow calculations the bearing capacity of piles with broadening via the bearing capacity of a prismatic pile is proposed. The equations are recommended to be used at the stage of variant design of piles with broadening as part of the pile foundations of buildings and structures.
\end{abstract}

\section{Keywords}

driven pile, broadening, equation, bearing capacity, correlation dependence

\section{Introduction}

In the pile foundation engineering, along with traditional prismatic piles, widely used piles with an unusual longitudinal shaft shape. There are well known driven piles with shaft broadening of the upper part and with broadening at the tip. The shape of the broadening can be pyramidal, cylindrical, gradient-prismatic, pyramidal-prismatic, etc. The results of studies of the behavior of piles with broadenings in various soil conditions reveal their significant efficiency in bearing capacity compared to standard piles.

The publications [1-7] are show that the presence of broadening at the upper part of the pile provides effective compaction of soft soils lying on the daily surface, and thereby causes an increase the bearing capacity of piles by 1.1-5.0 times. A significant positive factor of such piles is also the elimination of the gap emergence between the top of the pile and soil which can occur as a result of prismatic piles driving [8]. At the same time, the bearing capacity of piles depends on soil type and condition (the soil layering, the ability of the soil to dissipate the excess pore water pressure (hydraulic conductivity), the coefficient of radial (horizontal) consolidation etc.) [9], as well as on the shape and size of the broadening.

Kupchikova and Kurbatskiy [10] show that the bearing capacity of piles with the broadening at the upper part is increasing not only due to an increase in the square at the top but due to the changes of the work conditions of the soil on the lateral surface of pile and friction forces, which is implemented to a greater extent.

Movahedi Rad [11] concludes that penetration depth affects the lateral bearing capacity of piles. According to his results, with a greater depth of immersion, the pile, compressed by the soil, acts as an elasto-plastic frame 
rod structure with a certain resistance to bending [12]. This feature of the behavior of the pile in combination with the influence of the soil layer increases its passive resistance, which ultimately provides a large bearing capacity.

This statement is theoretically justified also Lógó et al. [13] when the semi-rigidity (i.e., the possibility of bending) of construction (e.g., piles) helps to increase its reliability under stress.

In a case when broadening located at the tip of the pile during pile driving leads to the formation of a compacted soil core under the pile tip. According to [14-19], this makes it possible to involve a larger volume of the soil stratum in the pile work, which ensures an increase the frontal resistance of the soil stratum to penetration of the pile tip. Such soil involvement can be beneficial in incoherent soils, since it can compact the surrounding soil [20] and, as a result, increase the overall bearing capacity of piles. As stated by Pusztai [21], this phenomenon is well turn up when piles with lower broadening are driven into incompressible granular layers stratum.

The presented research results, as can be seen, refer to piles having only one broadening, located either in the upper or in the lower part of the shaft. Therefore, these data cannot be extended to piles with several widening along the shaft. Such piles require additional research to identify both the distinctive features of their work and the behavior of the soil strata around them.

Considering an effective features of such widening piles, Bekbasarov et al. [22] have developed driven piles with several broadening along the shaft. These piles include a section of prismatic shape and broadening, which shape of each is close to the flat truncated pyramid form. Constructive novelty and prospects of using such piles necessitates studies the peculiarities of piles with several broadening of the shaft, including bearing capacity of last ones.

The authors performed studies to assess the bearing capacity of piles with several broadenings under the static pressing loads, which results are presented in this paper. Such comprehensive studies were conducted for the first time, so the results can be interesting to the reader. In addition, the authors, as shown below, were not limited only to a qualitative and quantitative analysis of the research results, but also proposed reasonable mathematical equations for calculating the bearing capacity of piles with broadening. Practical application of such equations certainly allows designing the new piles as a part of the pile foundations of buildings and structures, which indicates the practical value of the presented research results.

\subsection{Pile parameters}

Pile driven with several broadening along the shaft includes a prismatic shape section and the flat truncated pyramid shape broadening. In this research a pile have from 1 to 4 broadening (Fig. 1(a)). The height of each broadening is $1 \mathrm{~m}$, and the side's dimensions on the top of the broadening are $20 \times 45 \mathrm{~cm}$. The prismatic part of the pile has a square shape in cross section with dimensions of $20 \times 20 \mathrm{~cm}$. The total length of the pile is $5 \mathrm{~m}$ (Fig. 1(b)).

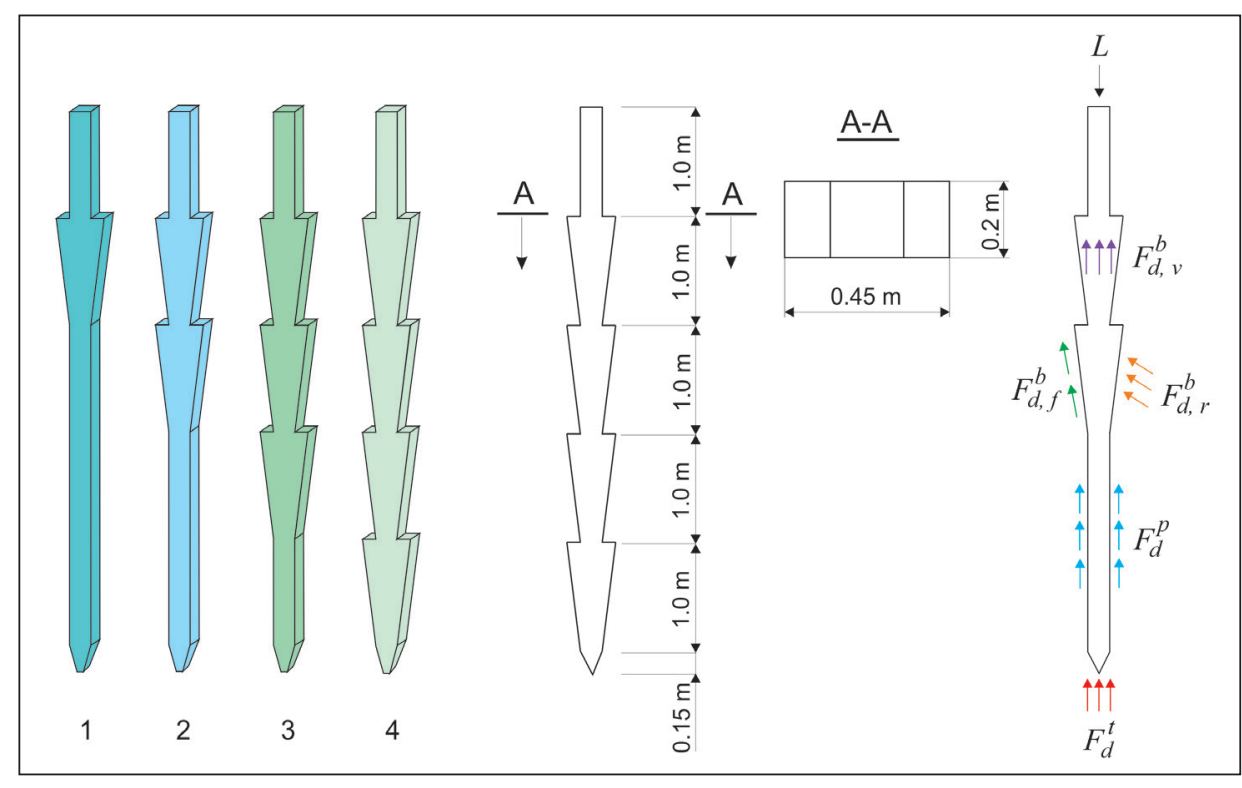

(a)

(b)

(c)

Fig. 1 Schematic view of piles with shaft broadening and bearing capacity components 


\section{Analytical approach}

To determine the bearing capacity of piles with broadening, at the first stage of study, necessitates obtaining mathematical equations, considering the peculiarities of their longitudinal shape.

Because of pile with broadening has a prismatic shape as well as pyramidal form, therefore the bearing capacity of the pile tip and its prismatic part can be determined as for a prismatic pile, and the bearing ability of broaden part can be determined as for several pyramidal piles of small height (except lower end).

It is well known that the bearing capacity of a prismatic pile and the bearing capacity of a pyramidal pile are calculated according to Eqs. (1) and (2) respectively, approved by ISBR 5.01-101-2003 [23].

$$
\begin{aligned}
& F_{d}=\gamma_{c}\left(\gamma_{c R} R A+u \sum \gamma_{c f} f_{i} h_{i}\right) \\
& F_{d}=\gamma_{c}\left[R A+\sum h_{i}\left(u_{i} f_{i}+u_{o i} i_{p} E_{i} k_{i} \zeta_{r}\right)\right.
\end{aligned}
$$

where $F_{d}$ is a bearing capacity of a pile, $N ; \gamma_{c}$ is coefficient of pile working conditions in the soil, taken equal to $1 ; \gamma_{c R}$, $\gamma_{c f}$ are coefficients of soil working conditions, respectively, under the lower end and lateral surface of the pile, taking into account the influence of pile immersion method on the calculated resistance of the soil (accepted according to tables of ISBR 5.01-101-2003); $A$ is a pile cross-sectional area, $\mathrm{m}^{2} ; u, u_{i}$ are pile section perimeters, $\mathrm{m} ; f_{i}$ is pile skin friction, $\mathrm{kN} / \mathrm{m} ; h_{i}$ is soil layer thickness, $\mathrm{m} ; R$ is a pile tip ultimate resistance; $u_{o i}$ is section perimeter inclined to the pile axis, $\mathrm{m} ; i_{p}$ is slope of the side faces; $E_{i}$ is modulus of deformation, $\mathrm{MPa} ; k_{i}$ is soil type coefficient, adopted according to the table of ISBR 5.01-101-2003; $\zeta_{r}$ is a rheological coefficient, taken equal to 0.8 .

The features of the longitudinal shape of the piles with broadening make it possible to distinguish the following components of their bearing capacity (Fig. 1(c)):

- the bearing capacity of the pile tip $F_{d}^{t}$;

- the bearing capacity of the prismatic part of pile along the lateral surface (below the last broadening) $F_{d}^{p}$;

- bearing capacity of the broadening of the pile shaft, which in turn may be divided into the following elements:

- the bearing capacity of the broaden part along their inclined faces, which is formed due to the friction forces of the soil $F_{d, f}^{b}$

- bearing capacity of the broadening along their inclined faces, which is formed due to the forces of soil repulsion $F_{d, r}^{b}$;
- bearing capacity of the broadening along their vertical faces due to the friction forces of the soil $F_{d, v}^{b}$.

It should be noted that the bearing ability of the prismatic part of the pile over the first upper broadening is not taken into account, because at the pile driving the soil surrounding becomes loose, therefore, the role of this prismatic part in providing the bearing capacity of the pile is negligible or close to zero.

The bearing capacities of the pile tip and prismatic part along the lateral surface (below the last broadening) can be determined as components included in Eq. (1). To determine the bearing capacity of the broadened part of the pile, it is possible to use the components included in Eq. (2).

Based on these arguments and considering the structural composition of Eqs. (1)-(2), the bearing capacity components of pile with shaft broaden may be written as follows:

$$
\begin{aligned}
& F_{d}^{t}=\gamma_{c} \gamma_{c R} R A, \\
& F_{d}^{p}=\gamma_{c} u_{p} \sum \gamma_{c f} f_{i p} h_{i p}, \\
& F_{d, f}^{b}=\gamma_{c} \sum h_{i b} u_{i b n} f_{i b}, \\
& F_{d, r}^{b}=\gamma_{c} \sum h_{i b} u_{i b n} i_{b} E_{i b} k_{i b} \zeta_{r}, \\
& F_{d, v}^{b}=\gamma_{c} \sum h_{i b} u_{i b v} f_{i b} .
\end{aligned}
$$

The mathematical structuring of Eqs. (3)-(7) allows us to obtain a formula for determining the bearing capacity of pile with broadening in the following final form

$$
\begin{aligned}
& F_{d}=\gamma_{c}\left\{\gamma_{c R} R A+\left[u_{p} \sum\left(\gamma_{c f, i} f_{p, i} h_{p, i}\right)\right]\right. \\
& +\left[\sum h_{b, i} f_{b, i}\left(u_{b v, i}+u_{b n, i}\right)\right] \\
& \left.+\left[\zeta_{r} i_{b} \sum\left(h_{b, i} u_{b n, i} E_{b, i} k_{b, i}\right)\right]\right\} .
\end{aligned}
$$

The presented equation is valid for piles with 1-3 broadens, having a prismatic part (below the last broadening), while for a pile with 4 broadens, Eq. (8) is written as follows

$$
\begin{aligned}
& F_{d}=\gamma_{c}\left\{\gamma_{c R} R A+\left[\sum h_{b, i} f_{b, i}\left(u_{b v, i}+u_{b n, i}\right)\right]\right. \\
& \left.+\left[\zeta_{r} i_{b} \sum\left(h_{b, i} u_{b n, i} E_{b, i} k_{b, i}\right)\right]\right\} .
\end{aligned}
$$

Equations (8)-(9) are obtained considering the geometric features of longitudinal shape of the piles with broadening.

All designations of parameters included in Eqs. (8)-(9) are correspond to the designations presented in [24]. 


\section{Numerical experiments}

Based on Eqs. (8)-(9), the load-bearing capacity of piles with 1-4 broadening of the shaft was calculated. The calculations were performed for clay soils of homogenous strata the following properties:

- liquidity index $0.3-0.7$;

- deformation modulus of 17.0 and $15.0 \mathrm{MPa}$;

- coefficient of soil porosity 0.69 .

For comparative analysis, similar calculations in the same soil layers were also performed for a traditional prismatic pile $5 \mathrm{~m}$ length. The cross-sectional dimensions of the prismatic pile were $20 \times 20 \mathrm{~cm}$. The bearing capacity of a prismatic pile was determined by Eq. (1).

The results of numerical experiments showed that new piles, compared to ordinary prismatic pile, have a greater bearing capacity (Table 1) [25]. For a comparative quantitative assessment of various types of piles by bearing capacity, the coefficient of relative efficiency of piles was used, which was taken as the ratio of the bearing capacity of piles with broadening to the same strength parameter of a prismatic pile (Table 2).

It was found that the bearing capacity of piles with broadening in 1.43-8.28 times higher than the bearing capacity of a prismatic pile (Table 2) [26]. Moreover, the difference in the bearing capacity of the compared piles depends on the liquidity index of soil and the number of broadenings (Fig. 2).

\section{Site investigation}

A series of field testing to experimentally compare the load-bearing capabilities of piles with shaft broadening and prismatic pile have been conducted. Field tests were carried out at the experimental site of "Kazakh Research and Design Institute of Construction and Architecture" SKB of JSC in sandy loam soil of homogenous strata. The physical and mechanical characteristics of the soil base were determined by penetration method using the PSG MG-4 device (Table 3). The tests have been conducted using semi-natural reinforced concrete models of piles made on a 1:3 modelling scale. A special device was assembled for driving and testing semi-natural models of piles [27].

Piles were immersed into the soil base by impact driving with a constant force of each impact (Fig. 3). A $40 \mathrm{~kg}$ weight hammer was dropped down from $0.5 \mathrm{~m}$ height. The piles penetration depth was $141.2-145.6 \mathrm{~cm}$ (maximum divergence $3.02 \%$ ).

Piles testing were conducted in accordance with ISBR 5.01-101-2003 [23]. The static loading was attached
Table 1 Calculated values of bearing capacity of piles

\begin{tabular}{lccccc}
\hline \multirow{2}{*}{ Pile type } & \multicolumn{5}{c}{ Values of bearing capacity $F_{d}, \mathrm{kN}$, at a rate of soil } \\
& 0.3 & 0.4 & 0.5 & 0.6 & 0.7 \\
\hline Pile 1 & 280.73 & 216.53 & 186.05 & 138.83 & 112.63 \\
Pile 2 & 368.96 & 302.63 & 271.28 & 213.33 & 186.01 \\
Pile 3 & 458.69 & 389.98 & 357.51 & 288.58 & 259.89 \\
Pile 4 & 541.77 & 472.63 & 439.91 & 361.1 & 332.19 \\
Prismatic pile & 196.25 & 133.05 & 102.95 & 65.83 & 40.13 \\
\hline
\end{tabular}

Table 2 Values of the coefficient of relative efficiency of piles by bearing capacity

\begin{tabular}{|c|c|c|c|c|}
\hline \multirow{2}{*}{ Soil liquidity index IL } & \multicolumn{4}{|c|}{ Coefficient values for piles } \\
\hline & pile 1 & pile 2 & pile 3 & pile 4 \\
\hline 0.3 & 1.43 & 1.88 & 2.34 & 2.76 \\
\hline 0.4 & 1.63 & 2.27 & 2.93 & 3.55 \\
\hline 0.5 & 1.81 & 2.64 & 3.47 & 4.27 \\
\hline 0.6 & 2.11 & 3.24 & 4.38 & 5.49 \\
\hline 0.7 & 2.81 & 4.64 & 6.48 & 8.28 \\
\hline
\end{tabular}

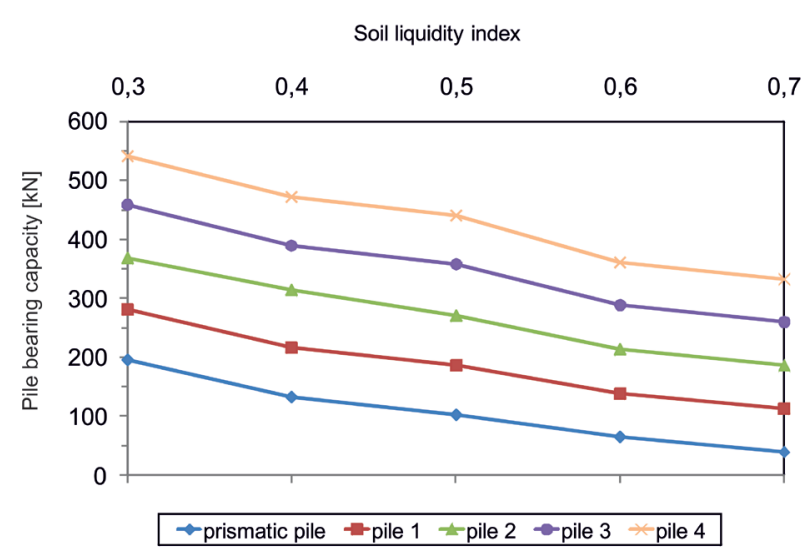

Fig. 2 Estimated bearing capacity of piles in various IL soils

Table 3 Properties of soil base used in the experimental site

\begin{tabular}{lc}
\hline Description & Value \\
\hline Water content, $w, \%$ & $3.16-5.58$ \\
Soil density, $\rho, \mathrm{kg} / \mathrm{m} 3$ & $1400-1670$ \\
Liquid limit, $W_{L}, \%$ & $24.18-24.37$ \\
Plastic limit, $W_{p}, \%$ & $17.30-17.47$ \\
Plasticity index, $I_{p}$ & $6.88-6.90$ \\
Maximum penetration resistance, $P_{\max }, \mathrm{MPa}$ & $1.47-1.62$ \\
Compaction ratio, $K$ & $0.89-0.94$ \\
Wetness index, $I_{w}$ & $0.75-0.84$ \\
Modulus of deformation, $E_{0}, \mathrm{MPa}$ & $31.6-33.6$ \\
Angel of internal friction, $\varphi$, grade & $17.1-17.6$ \\
Intercept cohesion, $c, \mathrm{MPa}$ & $0.018-0.019$ \\
\hline
\end{tabular}

stepwise, after completely stabilization of the deformation at the current loading stage (see Fig. 3). Piles displacement into depth was reached not less than $40 \mathrm{~mm}$ (Fig. 4). 

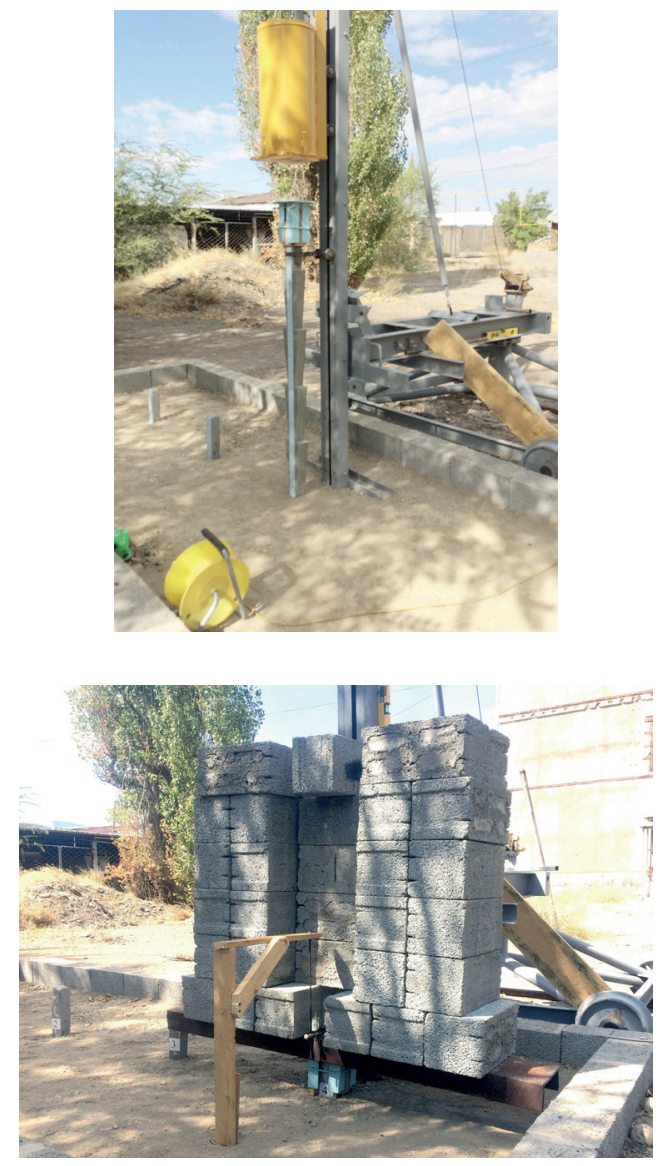

Fig. 3 Pile driving and static loading tests

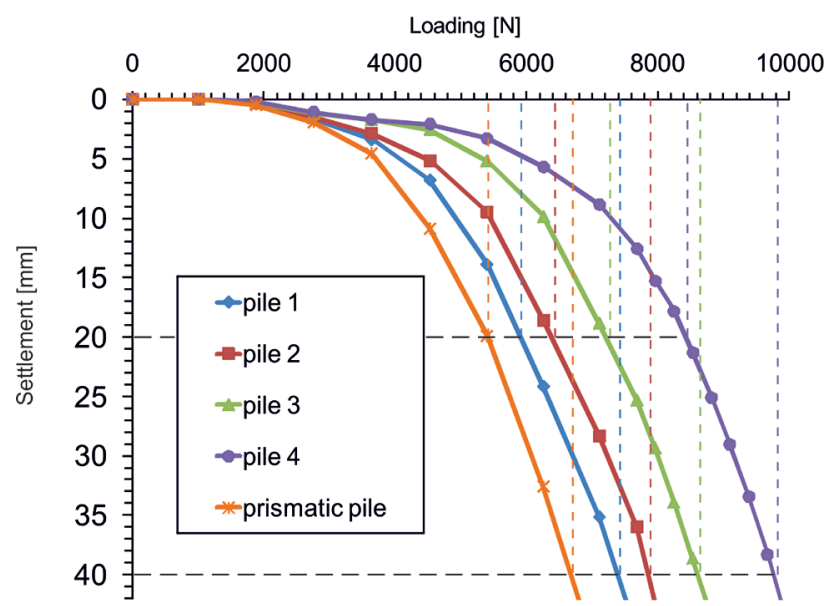

Fig. 4 Pile settlement depth versus static loading

The research results (Table 4) qualitatively confirm the above mentioned advantages of piles with shaft broadening (in bearing capacity), which were obtained by calculation.

Evaluation of the piles resistance to the pressing load was carried out by the coefficient of the relative efficiency of the piles depending on the bearing capacity $K_{H 1}^{p i}$, taken as the ratio of the bearing capacity value of the experimental pile to such power parameter value of the control pile (Table 5).
So, the bearing capacity of piles with broadening was 1.09-1.56 times higher than the same parameter of a prismatic pile according to the results of field tests of semi-natural piles (see Table 5).

A comparison of the data presented in tables 2 and 4 shows that the values of the coefficients obtained by numerical experiments exceed the coefficients values reached by the results of field static tests. Considering that the results of field experimental studies are more preferable than the results obtained by calculation methods, it is reasonable argued that the revealed incomplete identity of the calculated data with the experimental results indicates that Eqs. (1)-(2) in the present form allow obtaining some overstated results.

This circumstance requires revision and refinement of the calculation method for determining the bearing capacity of piles with broadening.

\section{Modification of calculation method}

An analysis of the structure and principles of the logical formation of Eqs. (8)-(9) shows their compliance with generally accepted construction rules adopted for Eqs. (1)-(2) of ISBR 5.01-101-2003 [23]. Therefore, the most probable reason for overestimating the results according to the considered equations is, in our opinion, that the actual total soil resistance under the inclined side faces of the entire broadenings is slightly lower than for the case when the pile would had a continuous inclination of the side faces. This is due to the fact that when the pile is immersed in under the each pile broadening (except the lowest broadening), the soil undergoes compaction, part of which become softer and moves into the cavity under inclined faces. This feature of soil behavior under pile broadenings, which appears during its immersion, should be taken into account in Eqs. (8)-(9).

\begin{tabular}{lcc}
\multicolumn{3}{c}{ Table 4 Bearing capacity of piles (according to field tests) } \\
\hline \multirow{2}{*}{ Pile type } & Values of bearing capacity $F_{d}, N$, at settlement \\
& $20 \mathrm{~mm}$ & $40 \mathrm{~mm}$ \\
\hline Pile 1 & 5915 & 7395 \\
Pile 2 & 6385 & 7860 \\
Pile 3 & 7215 & 8615 \\
Pile 4 & 8435 & 9760 \\
Prismatic pile & 5410 & 6685 \\
\hline
\end{tabular}

Table 5 Coefficient of relative efficiency of piles by bearing capacity $K_{\mu 1}^{p i}$ (according to field tests)

\begin{tabular}{ccccc}
\hline \multirow{2}{*}{ Pile settlement, mm } & \multicolumn{4}{c}{ Coefficient values for piles } \\
& pile 1 & pile 2 & pile 3 & pile 4 \\
\hline 20 & 1.09 & 1.18 & 1.33 & 1.56 \\
40 & 1.11 & 1.18 & 1.29 & 1.46 \\
\hline
\end{tabular}


Based on presented argues, it is advisable to include the appropriate coefficient in the structure of these equations. This coefficient is adopted to determine the share of the total soil resistance under the inclined side faces of the entire broaden part from the soil resistance force under the inclined side faces of the pile in case of their continuity along the shaft. Therefore, it was decided to clarify only that part of the bearing capacity of piles with broadening, which is formed due to soil resistance forces acting along the inclined side faces of the broadening.

Expression for determining of this coefficient value is used as follow equations.

For piles 1-3 (with 1-3 broadenings) is:

$K_{n u}=\left[\left(F_{d}^{p} \times K_{K 1}^{p i}\right)-\left(F_{d}^{R}+F_{d}^{p u}+F_{d}^{p n u}\right)\right] / F_{d}^{n u}$,

where $F_{d}^{p}$ is bearing capacity of a prismatic pile, determined by the Eq. (1), (calculated at numerical experiments); $K_{H 1}^{p i}$ is coefficient obtained by the results of field static tests (see Table 5); $F_{d}^{R}$ is bearing capacity of the pile tip; $F_{d}^{p u}$ is the bearing capacity of the flat side faces of pile broadening; $F_{d}^{p n u}$ is bearing capacity of prismatic part of the pile below the lower broadening (only for piles with 1-3 broadening); $F_{d}^{n u}$ is the bearing capacity of the inclined side faces of the broaden part.

For pile 4 (with 4 broadenings) as:

$K_{n u}=\left[\left(F_{d}^{p} \times K_{K 1}^{p i}\right)-\left(F_{d}^{R}+F_{d}^{p u}\right)\right] / F_{d}^{n u}$,

The coefficient $K_{n u}$, in accordance with the physical meaning adopted when it's determining, is hereinafter proposed to be called a coefficient considering the soil behavior under the broadening of the pile during immersion. The values of the coefficients, calculated by the Eqs. (10)-(11) are shown in Tables 6 and 7 .

The data presented in Tables 6 and 7 are mathematically describes by the following second-order polynomial function

$K_{n u}=a n^{2}-b n+c$,

where $n$ is the number of the pile broadening; $a, b$ and $c$ are parameters presented in Tables 8 and 9 depending on the liquidity index of clay soils.

A graphical expression of the coefficient values $K_{n u}$ for various soil liquidity indexes depending on the settlement depth of the piles is shown in Fig. 5.

Tables 8 and 9 as well as Fig. 5 are shown that the approximation indexes $\mathrm{R}^{\wedge} 2$ are close to, and in some cases an equal to 1.0, that's indicate a high reliability of the results obtained by Eq. (12). Therefore, this equation, as well as
Table 6 Coefficient values at pile settlement to $20 \mathrm{~mm}$

\begin{tabular}{lcccc}
\hline \multirow{2}{*}{ Soil liquidity index IL } & \multicolumn{4}{c}{ Coefficient values $K_{n u}$ for piles } \\
& pile 1 & pile 2 & pile 3 & pile 4 \\
\hline 0.3 & 0.22 & 0.23 & 0.28 & 0.36 \\
0.4 & 0.15 & 0.16 & 0.19 & 0.26 \\
0.5 & 0.12 & 0.13 & 0.15 & 0.2 \\
0.6 & 0.09 & 0.09 & 0.11 & 0.15 \\
0.7 & 0.05 & 0.06 & 0.07 & 0.09 \\
\hline
\end{tabular}

Table 7 Coefficient values at pile settlement to $40 \mathrm{~mm}$

\begin{tabular}{lcccc}
\hline Soil liquidity index IL & \multicolumn{4}{c}{ Coefficient values $K_{n u}$ for piles } \\
& pile 1 & pile 2 & pile 3 & pile 4 \\
\hline 0.3 & 0.27 & 0.23 & 0.25 & 0.31 \\
0.4 & 0.19 & 0.16 & 0.17 & 0.22 \\
0.5 & 0.15 & 0.13 & 0.14 & 0.17 \\
0.6 & 0.11 & 0.09 & 0.1 & 0.13 \\
0.7 & 0.06 & 0.06 & 0.06 & 0.08 \\
\hline
\end{tabular}

Table 8 Values of the parameters $a, b$ and $c$ at pile settlement to $20 \mathrm{~mm}$

\begin{tabular}{lcccc}
\hline $\begin{array}{l}\text { Soil liquidity } \\
\text { index IL }\end{array}$ & $a$ & $b$ & $c$ & $\begin{array}{c}\text { Approximation } \\
\text { index R`2 }\end{array}$ \\
\hline 0.3 & 0.017 & 0.040 & 0.242 & 0.999 \\
0.4 & 0.015 & 0.039 & 0.175 & 0.997 \\
0.5 & 0.01 & 0.024 & 0.135 & 0.994 \\
0.6 & 0.01 & 0.03 & 0.11 & 1.0 \\
0.7 & 0.002 & 0.000 & 0.047 & 0.994 \\
\hline
\end{tabular}

Table 9 Values of the parameters $a, b$ and $c$ at pile settlement to $40 \mathrm{~mm}$

\begin{tabular}{ccccc}
\hline $\begin{array}{c}\text { Soil liquidity } \\
\text { index IL }\end{array}$ & $a$ & $b$ & $c$ & $\begin{array}{c}\text { Approximation } \\
\text { index R^2 }\end{array}$ \\
\hline 0.3 & 0.025 & 0.111 & 0.355 & 0.994 \\
0.4 & 0.02 & 0.09 & 0.26 & 1.0 \\
0.5 & 0.012 & 0.055 & 0.192 & 0.994 \\
0.6 & 0.012 & 0.055 & 0.152 & 0.994 \\
0.7 & 0.005 & 0.019 & 0.075 & 0.933 \\
\hline
\end{tabular}

Tables 8 and 9, may be used to determine the value of the coefficient $K_{n u}$.

\section{Final calculations of the bearing capacity of piles}

\subsection{Approach 1}

Considering the coefficient, Eqs. (8)-(9) in the final version, will been as follow form

For piles 1-3 (with 1-3 broadenings) is

$$
\begin{aligned}
& F_{d}=\gamma_{c}\left\{\gamma_{c R} R A+\left[u_{p} \sum\left(\gamma_{c f, i} f_{p, i} h_{p, i}\right)\right]\right. \\
& +\left[\sum h_{b, i} f_{b, i}\left(u_{b v, i}+u_{b n, i}\right)\right] \\
& \left.+K_{n u}\left[\zeta_{r} i_{b} \sum\left(h_{b, i} u_{b n, i} E_{b, i} k_{b, i}\right)\right]\right\} .
\end{aligned}
$$




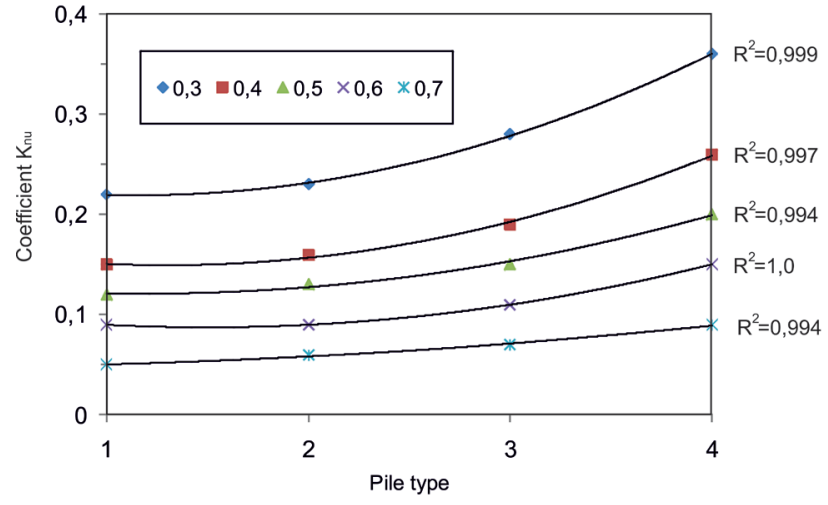

a) at the settlement of $20 \mathrm{~mm}$

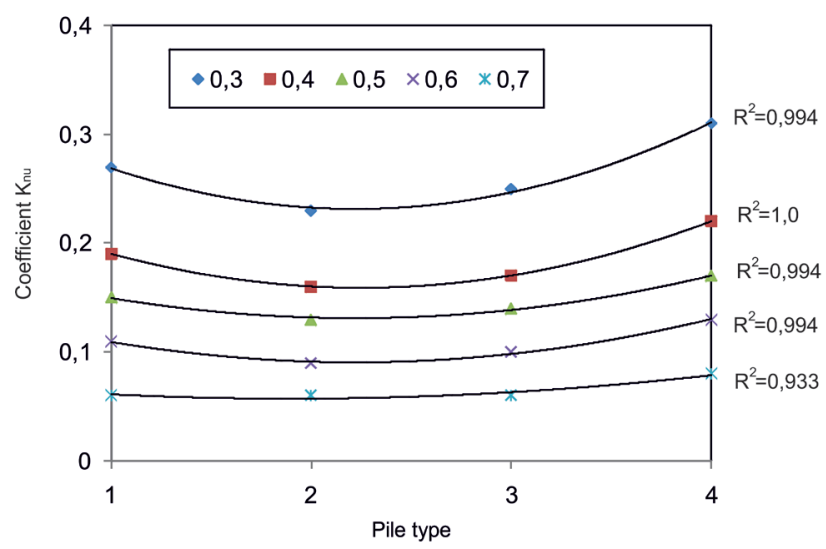

b) at the settlement of $40 \mathrm{~mm}$

Fig. $5 K_{n u}$ coefficient values for various soil liquidity indexes versus piles with broadening

For pile 4 (with 4 broadenings) as

$$
\begin{aligned}
& F_{d}=\gamma_{c}\left\{\gamma_{c R} R A+\left[\sum h_{b, i} f_{b, i}\left(u_{b v, i}+u_{b n, i}\right)\right]\right. \\
& \left.+K_{n u}\left[\zeta_{r} i_{b} \sum\left(h_{b, i} u_{b n, i} E_{b, i} k_{b, i}\right)\right]\right\} .
\end{aligned}
$$

Based on the presented equations, verification calculations of the bearing capacity of piles with broadening were re-performed. As the results showed calculations error according to Eqs. (13)-(14) does not exceed $2 \%$, which indicates a high reliability of obtained results.

\subsection{Approach 2}

An analysis of the study results showed that to determine the bearing capacity of piles with broadening, along with Eqs. (13)-(14), a more simplified approach can be used also. This approach is expressed in applying of the following correlation dependence obtained on the basis of processing of the pile field tests results

$F_{d}=F_{d}^{p}+\Delta F$ where $F_{d}^{p}$ is the bearing capacity of a prismatic pile, $\mathrm{kN}$; $\Delta F$ is an additional to $F_{d}^{p}$ bearing capacity of the pile, due to the existence and action of broaden part of pile, $\mathrm{kN}$.

An additional bearing capacity of piles in Eq. (15) is determined by the following expression

$\Delta F=\eta\left(g n^{2}-p n+t\right) / 10^{3}$,

where $\eta$ is a parameter considering the scale multiplier of the piles and taken an equal to 9.0 [6]; $g, p$ and $t$ are parameters presented in Table 10, obtained depending on the settlement of the pile; $n$ is number of pile broadening.

Eqs. (13)-(15) are recommended for use at the design of pile foundations from piles with shaft broadening.

At the variant design stage of using prismatic piles and piles with shaft broadening calculations are proposed to be carried out at compliance to the following conditions:

- the cross-sectional shape of the prismatic pile must be a square shape, and the sides dimensions of the cross-section of the prismatic part of the pile with broadening must conform to sides dimensions of prismatic pile;

- the length and depth of immersion of prismatic piles and piles with broadening should be the same.

\section{Conclusions}

The results of experimental studies and a numerical calculation procedure for vertical bearing capacity of driven piles with shaft broadening have been presented in this study. Comparative studies conducted between piles with 1-4 broadening of the shaft and a prismatic pile with a cross-section size of $20 \times 20 \mathrm{~cm}$. Compared with the ordinary prismatic pile, the proposed piles have a significantly greater bearing capacity. Estimated bearing capacity of piles with broadening was calculated by equations, proposed considering with the features of geometric form of piles, an experimental bearing ability was obtained in the field testing of semi-natural models of piles. The constituent components of the bearing capacity of the pile with shaft broadening in numerical calculations have been formed depending on the features of the longitudinal shape of the pile.

Table 10 Values of parameters $g, p$ and $t$

\begin{tabular}{lcccc}
\hline $\begin{array}{l}\text { Pile settlement, } \\
\mathrm{mm}\end{array}$ & \multicolumn{3}{c}{ Parameter values } & $\begin{array}{c}\text { Approximation } \\
\text { index R^2 }\end{array}$ \\
\hline 20 & $g$ & $p$ & $t$ & 1.0 \\
40 & 187.5 & 98.5 & 417.5 & 0.999 \\
\hline
\end{tabular}


Based on verification of equations proposed by the authors, a coefficient was included in the formulas, which is considered the peculiarities of the soil behavior under the pile broadening during it immersion. The values of this coefficient were proposed to be determining using the correlation dependence on the basis of the number of pile broadening and the soil liquidity index. As an alternative approach, the load-bearing ability of piles with broadening was proposed to determine through the same parameters of the prismatic pile using an equation of correlation dependence.

At the variant design case of using prismatic piles and piles with shaft broadening calculations proposed to carry at compliance of similarity of piles parameters. It should

\section{References}

[1] Sesyunin, S. G., Levi, S. R., Potapov, A. D. "The choice of the optimal design of reinforced concrete driven piles for heaving soil", MGSU Bulletin, 3, pp. 167-172, 2009. [online] Available at: https:// cyberleninka.ru/article/n/vybor-optimalnoy-konstruktsii-zhelezobetonnoy-zabivnoy-svai-dlya-puchinistogo-grunta-1 (in Russian)

[2] Buslov, A. S., Bakulina, A. A. "The effect of annular broadens on the bearing capacity of a horizontally loaded mono-pile support", MGSU Bulletin, 4, pp. 63-68, 2012. [online] Available at: https:// cyberleninka.ru/article/n/vliyanie-koltsevogo-ushireniya-na-nesuschuyu-sposobnost-gorizontalno-nagruzhennoy-monosvaynoy-opory-1 (in Russian)

[3] Bulatov, G. Y., Kolosova, N. B., Kolosov, E. S., Teplov, A. B. "Bearing capacity of driven piles with different types of cross section", Construction of Unique Buildings and Structures, 10(15), pp. 15-24, 2013.

https://doi.org/10.18720/CUBS.15.2

[4] Bekbasarov, I. I., Baiteliyev, R. T., Shilibekov, S. K., Isakov, G. I. "New promising resource-saving pile structures", Herald of the Perm National Research Polytechnic University "Construction and Architecture", 4, pp. 81-92, 2014. [online] Available at: https:// cyberleninka.ru/article/n/novye-perspektivnye-resursosberegayuschie-svaynye-konstruktsii (in Russian)

[5] Sokolov, L. Y. "The rational form of a single-pile foundation for columns of industrial buildings and structures", Bulletin of the Kazan State Architectural and Construction University, 1(27), pp. 131-139, 2014. [online] Available at: https://www.elibrary.ru/item. asp?id=21518948 (in Russian)

[6] Bekbasarov, I. I., Isakov, G. I., Amanbai, A. "Immersion and energy intensity of driving piles and dies", Lap Lambert Academic Publishing, Saarbrucken, Germany, 2014.

[7] Kupchikova, N. V. "Proposals for supplementing the classification of structures of finished and rammed piles with broadening at the top and inclined lateral piles", Engineering and Construction Bulletin of the Caspian Sea Littoral, Astrakhan Engineering and Construction Institute, 1(11), pp. 25-35, 2015. [online] Available at: https://xn--80aaildk.xn--plai/journal/files/documents/44-redaktor/isvp_1_11/isvp_2015-1-25-35.pdf(in Russian) be noted that comply with the terms at using proposed equations to determine the bearing capacity of piles with broadening will allow to be rationally designed them and, therefore, used under the supports of buildings and structures, including hydraulic structures.

\section{Acknowledgements}

The authors grateful to Mr. Baitemirov Mukhan, Director of "Kazakh Research and Design Institute of Construction and Architecture" SKB of JSC and Mr. Shanshabayev Nurzhan, post graduate student of the Dulaty University for their advice and assistance in conducting field tests of pile models.

[8] Isaev, V. I., Maltsev, A. V., Karpov, A. A. "Comparative Evaluation of Bearing Capacity of a Short Driven Pyramidal-prismatic Pile Using Mathematical Models", Procedia Engineering, 153, pp. 223$227,2016$.

https://doi.org/10.1016/j.proeng.2016.08.106

[9] Ahlinhan, M. F., Adjovi, E. C. "Setup of axial bearing capacity of open ended tubular steel piles driven in sand", Studia Geotechnica et Mechanica, 42(1), pp. 74-82, 2020.

https://doi.org/10.2478/sgem-2019-0032

[10] Kupchikova, N. V., Kurbatskiy, E. N. "Analytical Method Used to Calculate Pile Foundations with the Widening Up on a Horizontal Static Impact", IOP Conference Series: Materials Science and Engineering, 262, Article number: 012102, 2017.

https://doi.org/10.1088/1757-899X/262/1/012102

[11] Movahedi Rad, M. "Reliability Based Analysis and Optimum Design of Laterally Loaded Piles", Periodica Polytechnica Civil Engineering, 61(3), pp. 491-497, 2017. https://doi.org/10.3311/PPci.8756

[12] Movahedi Rad, M. "A Review of Elasto-Plastic Shakedown Analysis with Limited Plastic Deformations and Displacements", Periodica Polytechnica Civil Engineering, 62(3), pp. 812-817, 2018. https://doi.org/10.3311/PPci.11696

[13] Lógó, J., Movahedi Rad, M., Knabel, J., Tauzowski, P. "Reliability based design of frames with limited residual strain energy capacity", Periodica Polytechnica Civil Engineering, 55(1), pp. 13-20, 2011. https://doi.org/10.3311/pp.ci.2011-1.02

[14] Sedin, V. L., Shvets, V. B., Alekseyev, A. I., Zakhvatkin, M. P., Bikus, K. M. "The experience of researching the pile action of various shapes in conditions of soft soils", To the 80th anniversary of the Dnieper State Academy of Civil Engineering and Architecture, 9, pp. 35-40, 2010. [online] Available at: https://cyberleninka.ru/article/n/opyt-issledovaniya-raboty-svay-razlichnoy-formy-v-usloviyah-slabyh-gruntov (in Russian)

[15] Glukhov, V. S., Glukhova, M. V. "Time-varying deformations of locally compacted basement soil under the piles with broadening", In: The first USA - Russia geotechnical engineering workshop, Moscow, Russia, March, 25-28, 2014. [online] Available at: http:// novotech.ru/rukovoditel/publikatsii/stati/timevarying_deformations_of_locally_compacted_basement_soil_under_the_piles with_broadening (in Russian) 
[16] Buslov, A. S., Mokhovikov, E. S. "Bearing capacity of a horizontally loaded single pile support with pits", Herald of the Moscow State Construction University, 9, pp. 51-60, 2015. [online] Available at: https://www.elibrary.ru/item.asp?id=24213163 (in Russian)

[17] Kupchikova, N. V. "Numerical researches of the work of the pile with end spherical broadening as part of the pile group", Construction and Reconstruction, 6(86), pp. 3-9, 2019.

https://doi.org/10.33979/2073-7416-2019-86-6-3-9

[18] Bekbasarov, I. I. "About the form of the lower end of the pile when assessing the energy intensity of its driving and bearing capacity", Kazakhstan Science News, 4(138), pp. 166-178, 2018.

[19] Samokhvalov, M., Geidt, A., Paronko, A. "Analysis of the Settlement of New Construction Drill-Injection Pile with Broadening at the End in Silty-Clayed Soils", In: Petriaev, A., Kanon, A. (eds.) Transportation Soil Engineering in Cold Regions, Springer, Singapore, 2020, pp. 487-497.

https://doi.org/10.1007/978-981-15-0450-1_51

[20] Hosseini, M. A, Rayhani, M. "Evolution of pile shaft capacity over time in marine soils", International Journal of Geo-Engineering, 8, Article number: 12, 2017. https://doi.org/10.1186/s40703-017-0049-8

[21] Pusztai, J. "Contribution to determining the load bearing capacity of Franki piles", Periodica Polytechnica Civil Engineering, 48(1-2), pp. 47-52, 2004.

https://pp.bme.hu/ci/article/view/581
[22] Bekbasarov, I. I., Isakov, G. I. "Hammered reinforced concrete pile", National Institute of Intellectual Property, Astana, Kazakhstan, Patent No. 76564, 2012.

[23] "Interstate Code of Practice ISBR 5.01-101-2003 Design and construction of pile foundations", National Institute of Intellectual Property, Astana, Kazakhstan, 2007.

[24] Bekbasarov, I. I., Atenov, Y. I. "A method for determining the bearing capacity of a hanging driven pile with flat pyramidal broadening of the shaft", National Institute of Intellectual Property, Astana, Kazakhstan, Patent No. 4387, 2019.

[25] Bekbasarov, I. I., Atenov, Y. I. "About the bearing capacity of driven piles with flat broadening of the shaft", In: International Scientific and Practical Conference "Actual Problems and Prospects for the Development of Building Structures: Innovation, Modernization and Energy Efficiency in Construction", Almaty, Kazakhstan, 2018, pp. 123-128.

[26] Bekbasarov, I. I., Atenov, Y. I. "A comparative assessment of the bearing capacity of piles with different longitudinal shapes" In: The 13th International Conference "Innovative development and the demand for science in modern Kazakhstan", Taraz, Kazakhstan, 2019, pp. 24-25.

[27] Bekbasarov, I. I., Baitemirov, M. N., Atenov, Y. I., Shanshabayev, N. A. "On experimental equipment for driving and testing largescale models of piles in site", Mechanics and Technologies, 66(4), pp. 134-141, 2019. 